\title{
Bone Marrow Metastasis of Rhabdomyosarcoma Mimicking Acute Leukemia: A Case Report and Review of the Literature
}

\author{
Yuka Aida ${ }^{1}$, Toshimitsu Ueki ${ }^{1}$, Takehiko Kirihara ${ }^{1}$, Wataru Takeda ${ }^{1}$, Taro Kurihara ${ }^{1}$, \\ Keijiro Sato ${ }^{1}$, Ikuo Shimizu ${ }^{1}$, Yuki Hiroshima ${ }^{1}$, Masahiko Sumi ${ }^{1}$, Mayumi Ueno ${ }^{1}$, \\ Naoaki Ichikawa ${ }^{1}$, Masahide Watanabe ${ }^{2}$ and Hikaru Kobayashi ${ }^{1}$
}

\begin{abstract}
Bone marrow metastasis of rhabdomyosarcoma has been reported to be difficult to distinguish from acute leukemia. We herein describe a case of rhabdomyosarcoma with bone marrow metastasis mimicking acute lymphoblastic leukemia. A 29-year-old woman was admitted with thrombocytopenia, blast-like cells in the peripheral blood and a coagulation disorder. Bone marrow aspirates showed $94.8 \%$ blast-like cell infiltration (CD45, myeloperoxidase, and $\mathrm{CD}^{-} 6^{+}$), and CT scan revealed the presence of an infiltrating mass in the nasal cavity. Based on a biopsy of the nasal cavity, the patient was diagnosed with rhabdomyosarcoma exhibiting bone marrow metastasis. She received chemotherapy, followed by radiation therapy, and has since remained alive for 26 months, as of the last follow-up.
\end{abstract}

Key words: rhabdomyosarcoma, alveolar, bone marrow metastasis, acute leukemia, disseminated intravascular coagulation, VDC EI

(Intern Med 54: 643-650, 2015)

(DOI: 10.2169/internalmedicine.54.2473)

\section{Introduction}

Some rare malignant diseases exhibit clinical features and bone marrow aspirate morphology similar to that of acute leukemia. For instance, rhabdomyosarcoma, neuroblastoma (1), medulloblastoma (2), anaplastic oligodendroglioma (3), small cell carcinoma, Ewing's sarcoma and neuroendocrine tumors have been reported to display an acute leukemia-like morphology in bone marrow aspirates after metastasizing to the bone marrow. Among these lesions, rhabdomyosarcoma, a soft tissue sarcoma that is primarily observed in childhood and adolescence $(4,5)$, is particularly difficult to distinguish from acute leukemia based on bone marrow aspirate morphology. Indeed, some cases have been diagnosed and treated as leukemia due to the presence of blast-like cells in bone marrow aspirates $(4,6-10)$. We herein describe a case of alveolar rhab- domyosarcoma in the nasal cavity with bone marrow metastasis mimicking acute lymphoblastic leukemia.

\section{Case Report}

A 29-year-old woman presented with epistaxis in August 2011. She first felt glabellar pain in early September and later experienced a headache, fever and malaise. In October, her chest pain worsened, and she visited an orthopedic clinic. A CT scan revealed a fractured sternum, and the laboratory data showed thrombocytopenia and the appearance of abnormal blast-like cells in the peripheral blood. The patient was then referred to our hospital.

On admission, a physical examination revealed pallor and swelling of the sternum. Purpuric lesions and hematomas were also observed in the left forearm and both lower extremities. The laboratory findings are described in Tables 1 and 2, as follows: white blood cells $=6.6 \times 10^{9} / \mathrm{L}$ with

${ }^{1}$ Department of Hematology, Nagano Red Cross Hospital, Japan and ${ }^{2}$ Department of Pathology, Nagano Red Cross Hospital, Japan Received for publication January 13, 2014; Accepted for publication July 27, 2014 Correspondence to Dr. Toshimitsu Ueki, toshimitsu-u@h9.dion.ne.jp 
Table 1. Laboratory Data

\begin{tabular}{cllllc}
\hline Peripheral blood & \multicolumn{2}{c}{ Blood chemistry } & \multicolumn{2}{c}{ Blood coagulation } \\
WBC & $6,600 / \mu \mathrm{L}$ & $\mathrm{TP}$ & $7.1 \mathrm{~g} / \mathrm{dL}$ & PT & $12.6 \mathrm{sec}$ \\
Blast & $1 \%$ & Alb & $4.2 \mathrm{~g} / \mathrm{dL}$ & PT-INR & 1.15 \\
Myelo & $6 \%$ & BUN & $11.5 \mathrm{mg} / \mathrm{dL}$ & APTT & $30.5 \mathrm{sec}$ \\
Meta & $5 \%$ & Cr & $0.73 \mathrm{mg} / \mathrm{dL}$ & Fibrinogen & $212 \mathrm{mg} / \mathrm{dL}$ \\
Stab & $20 \%$ & UA & $8.1 \mathrm{mg} / \mathrm{dL}$ & D-dimer & $43.4 \mathrm{\mu g} / \mathrm{mL}$ \\
Seg & $39 \%$ & T-bil & $0.5 \mathrm{mg} / \mathrm{dL}$ & FDP & $93 \mu \mathrm{g} / \mathrm{mL}$ \\
Eos & $0 \%$ & D-bil & $0.2 \mathrm{mg} / \mathrm{dL}$ & ATII & $139 \%$ \\
Baso & $0 \%$ & AST & $49 \mathrm{IU} / \mathrm{L}$ & TAT & $>60.0 \mathrm{ng} / \mathrm{mL}$ \\
Mono & $1 \%$ & ALT & $20 \mathrm{IU} / \mathrm{L}$ & PIC & $9.1 \mathrm{\mu g} / \mathrm{mL}$ \\
Lymp & $27 \%$ & LDH & $983 \mathrm{IU} / \mathrm{L}$ & & \\
Aty-L & $1 \%$ & LDH1 & $17 \%$ & & \\
RBC & $401 * 10^{4}$ & LDH2 & $37 \%$ & & \\
Hgb & $12.3 \mathrm{~g} / \mathrm{dL}$ & LDH3 & $30 \%$ & & \\
MCV & $90 \mathrm{fL}$ & LDH 4 & $11 \%$ & & \\
MCHC & $34.2 \%$ & LDH5 & $5 \%$ & & \\
Ret & $3.0^{*} 10^{4} / \mu \mathrm{L}$ & ALP & $112 \mathrm{IU} / \mathrm{L}$ & & \\
Plt & $5.6 / 10^{4} / \mu \mathrm{L}$ & CRP & $0.04 \mathrm{mg} / \mathrm{dL}$ & & \\
\hline
\end{tabular}

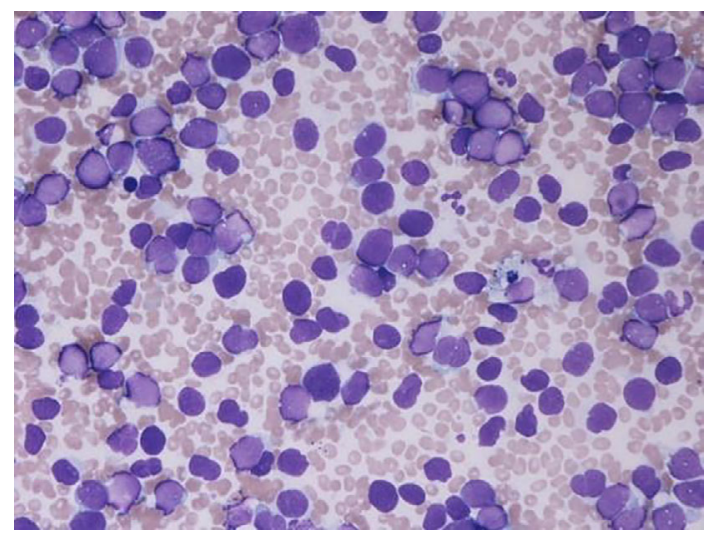

Figure 1. May Giemsa stained bone marrow smears showing diffuse infiltration with a large number of large blast-like cells.

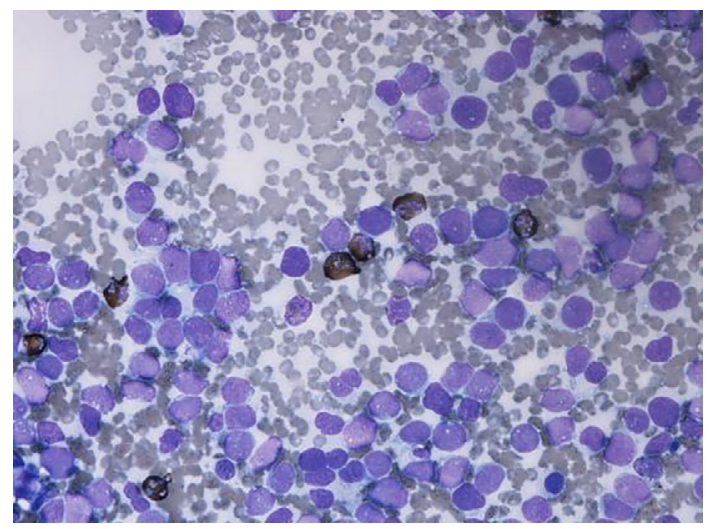

Figure 3. Aspirate smears showing the absence of staining with peroxidase in the malignant cells.

blasts $1.0 \%$, platelets $=56 \times 10^{9} / \mathrm{L}$, D-dimer $=43.4 \mu \mathrm{g} / \mathrm{mL}$, fibrin degradation product $(\mathrm{FDP})=93 \mu \mathrm{g} / \mathrm{mL}$. A bone marrow aspirate sampled obtained on admission showed $94.8 \%$ blast-like cells, which were essentially myeloperoxidase (MPO) negative (Fig. 1-3). These cells were intermediate to large in size, with prominent nucleoli and vacuolation, similar to that observed in cases of acute lymphoid leukemia. The results

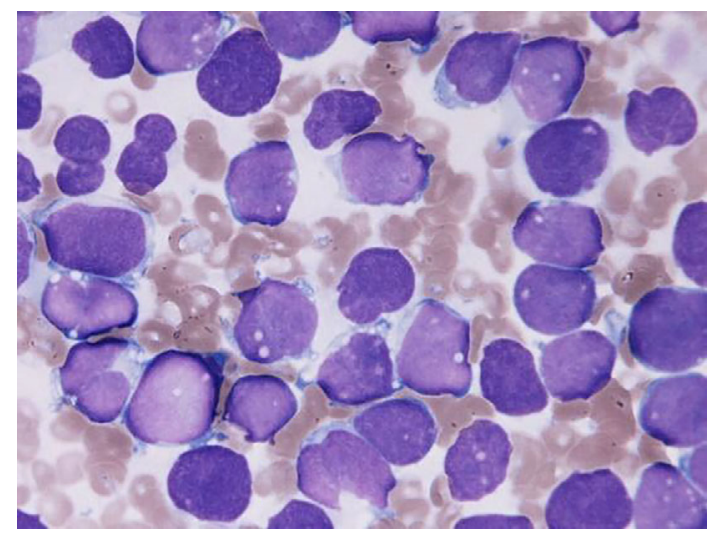

Figure 2. (Enlarged image of Fig. 1). The cells were intermediate to large in size with large hyperchromatic and prominent nucleoli and vacuolation, similar to that observed in cases of acute lymphoid leukemia.

of a flow cytometry analysis of the bone marrow aspirates obtained on admission were available on day 3 , showing the blast-like cells to be CD56-positive, although they did not express CD45 or other lymphoid or myeloid antigens (Fig. 4). Based on an MRI examination performed on day 5, which showed a contrasted mass infiltrating from the right nasal cavity to the ethmoid sinus (Fig. 5), and an $18 \mathrm{~F}$ fluoro 2 deoxy D glucose (18F-FDG)-positron emission tomography study performed on day 6 , which demonstrated a high level of accumulation in the bone marrow, including the sternum, and extending from the right nasal cavity to the ethmoid sinus. A biopsy of the nasal cavity performed on day 6 after admission revealed proliferating cells with a high nuclear-cytoplasmic ratio with uniform solid nests arranged in palisades on Hematoxylin and Eosin staining, implying a diagnosis of alveolar rhabdomyosarcoma (Fig. 6- Hematoxylin and Eosin). Therefore, a tentative diagnosis of alveolar rhabdomyosarcoma of the nasal cavity with bone marrow metastasis was made.

After the biopsy, disseminated intravascular coagulation (DIC) rapidly worsened (i.e., the fibrinogen level decreased 
Hematoxylin and Eosin

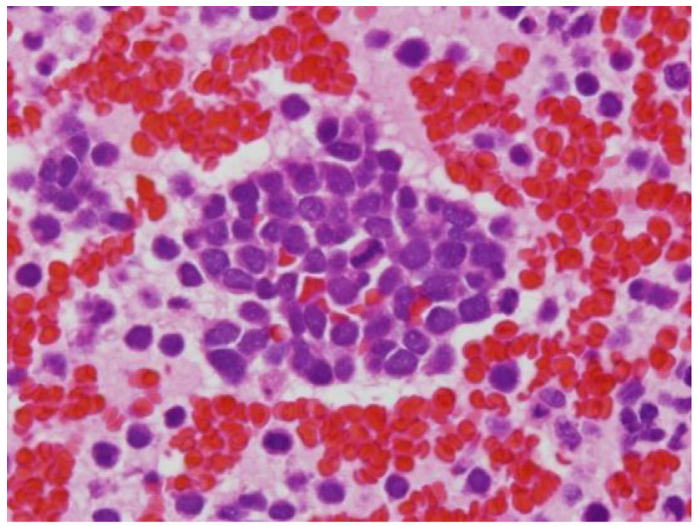

CD34

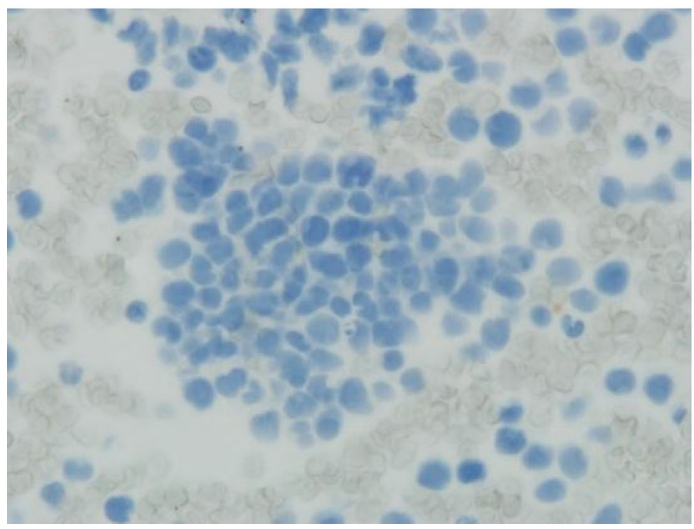

CD45

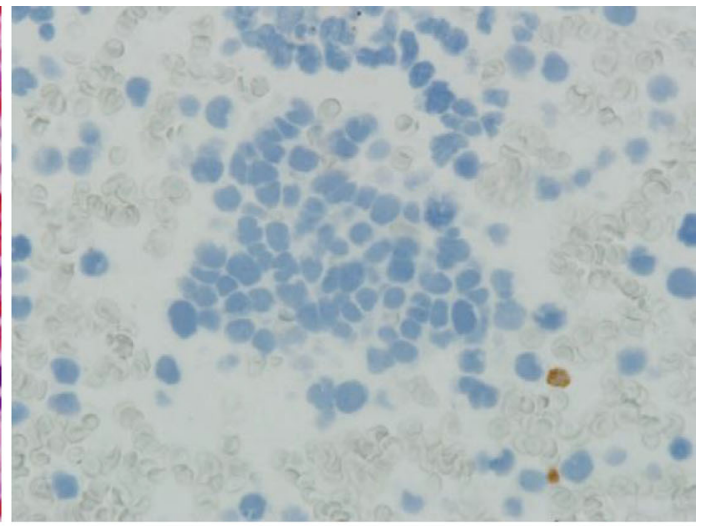

\section{CD56}

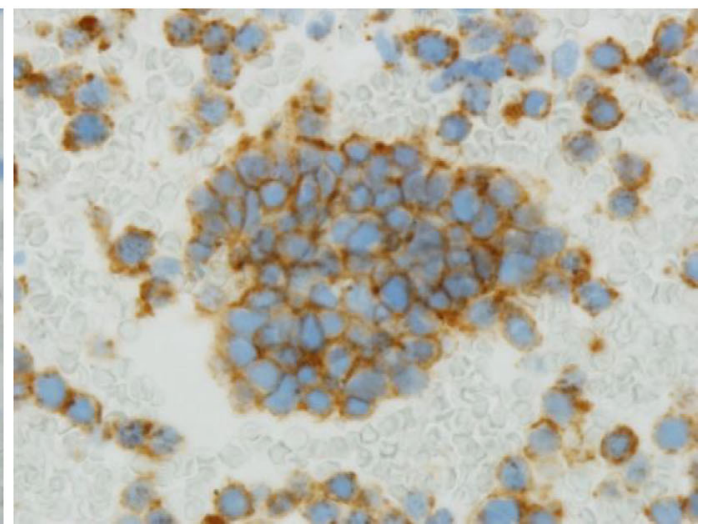

Figure 4. A bone marrow biopsy demonstrated that the tumor cells were positive for only CD56 and negative for both myeloid and lymphoid markers.

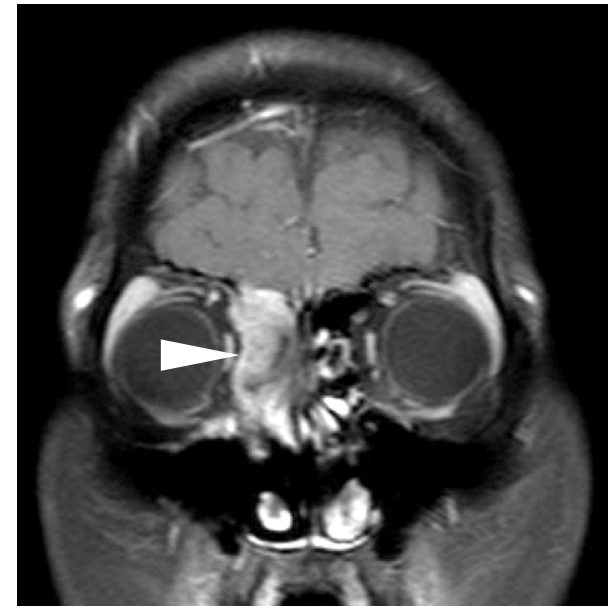

Figure 5. Magnetic resonance image showing a contrasted mass infiltrating from the right nasal cavity to the ethmoid sinus.

to $120 \mathrm{mg} / \mathrm{dL}$, the D-dimer level increased to $255 \mu \mathrm{g} / \mathrm{mL}$ and the FDP level increased to $580 \mu \mathrm{g} / \mathrm{mL}$ ) on day 7 , and it became difficult to control the bleeding from the site of the biopsy of the nasal tumor. Given the urgency to initiate treatment, before obtaining the definitive diagnosis, the patient was tentatively diagnosed with rhabdomyosarcoma based on the results of a flow cytometry analysis of the bone marrow cells and the distinctive morphological pattern of the biopsied nasal cavity specimen. Treatment with alternating cycles of VDC [vincristine (VCR), doxorubicin (DXR), cyclophosphamide (CPA)] and etoposide, iphosphamide (EI) (11) followed by radiation therapy was initiated starting on day 8 after admission.

The treatment course is shown in Fig. 7. Specifically, the patient received VCR at a dose of $1.5 \mathrm{mg} / \mathrm{m}^{2}$ (maximum dose: $2 \mathrm{mg}$ ), DXR at a dose of $37.5 \mathrm{mg} / \mathrm{m}^{2} /$ day as a daily 18-hour infusion for two days and CPA at a dose of 600 $\mathrm{mg} / \mathrm{m}^{2} /$ day for two days with mesna at a dose of $360 \mathrm{mg} / \mathrm{m}^{2}$ / dose for five doses each day at weeks 0, 6, 12, 18, 24 and 30. In addition, etoposide was administered at a dose of 100 $\mathrm{mg} / \mathrm{m}^{2} /$ day for five days with ifosfamide at a dose of 1,800 $\mathrm{mg} / \mathrm{m}^{2} /$ day for five days and mesna at a dose of $360 \mathrm{mg} / \mathrm{m}^{2} /$ dose for five doses at weeks 3, 9, 15, 21, 27, 33, 36 and 39. Finally, VCR was also administered at weeks 1, 2, 7 and 8. Triple intrathecal chemotherapy was omitted, as there was no evidence of central nervous system (CNS) invasion. After week 12 (following four cycles of chemotherapy), the patient received irradiation as primary local therapy at a dose of 5,040 cGy in 28 fractions to the tumor, followed by an additional boost of 540 cGy.

In order to reduce the potential for tumor lysis syndrome, 
Hematoxylin and Eosin

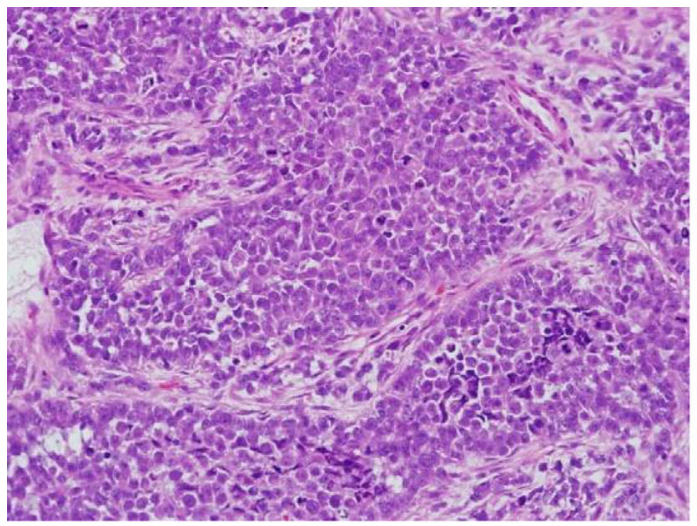

Desmin

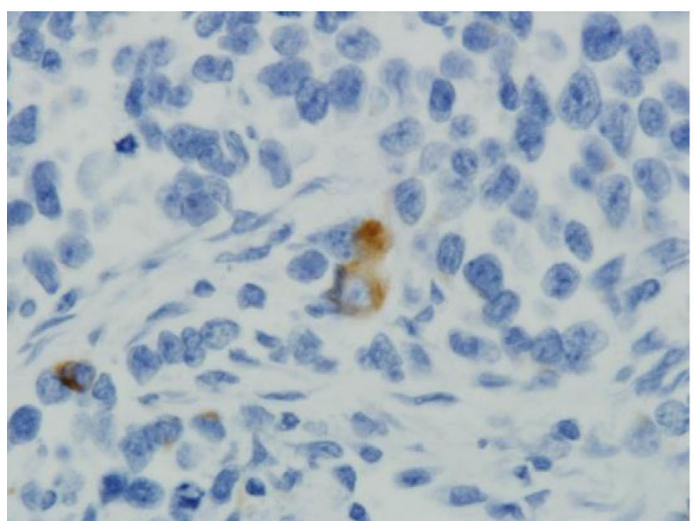

CD56

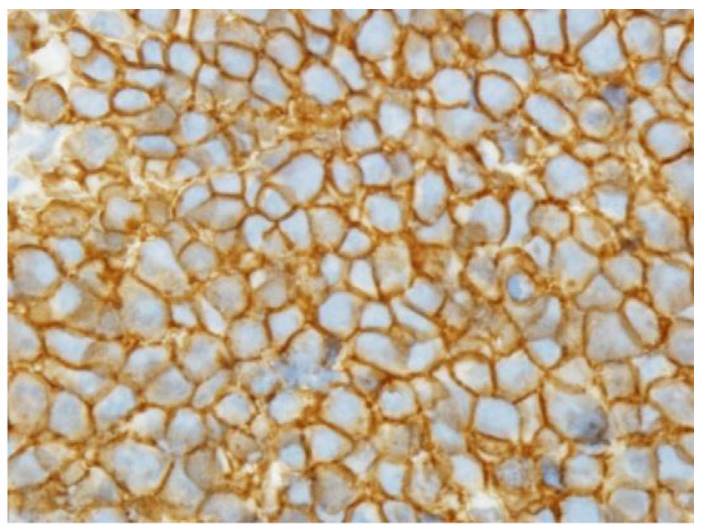

Figure 6. Biopsy of the nasal cavity. Immunohistochemistry showed most tumor cells to be highly positive for CD56 and partially positive for desmin.

\begin{tabular}{|c|c|c|c|c|c|c|c|c|}
\hline Induction & & & & & & & & \\
\hline week & 0 & 1 & 2 & 3 & 6 & 7 & 8 & 9 \\
\hline & V & V & V & E & V & V & V & E \\
\hline & D & & & I & D & & & I \\
\hline & C & & & & C & & & \\
\hline Consolidation & & & & & & & & \\
\hline week & $12 *$ & 15 & $18 \#$ & & & & & \\
\hline & V & E & V & & & & & \\
\hline & D & I & C & & & & & \\
\hline & C & & & & & & & \\
\hline & & & & & & & & \\
\hline Maintenance & & & & & & & & \\
\hline week & 21 & 24 & 27 & 30 & 33 & 36 & 39 & \\
\hline & E & V & E & V & E & V & E & \\
\hline & I & D & I & D & I & D & I & \\
\hline & & C & & C & & C & & \\
\hline & & & & & & & & \\
\hline
\end{tabular}

Figure 7. V: VCR $1.5 \mathrm{mg} / \mathrm{m}^{2}$ (max $\left.2 \mathrm{mg}\right)$. D: DXR $37.5 \mathrm{mg} / \mathrm{m}^{2}$ 2 days. C: CPA $600 \mathrm{mg} / \mathrm{m}^{2} /$ day 2 days. E: Etoposide $100 \mathrm{mg} / \mathrm{m}^{2} /$ day 5 days. I: Ifosfamide $1,800 \mathrm{mg} / \mathrm{m}^{2} 5$ days. *: Patients receiving irradiation to the nasal tumor as primary local therapy began treatment at week 12 after completing DXR at a dose of $5,040 \mathrm{cGy} / 28$ Frac followed by an additional boost of $540 \mathrm{cGy} / 3$ Frac. \#: At week 18, DXR was omitted due to the administration of additional radiation therapy. the first doses of VCR, DXR and CPA were administered separately over the course of a few days. An immunohistochemical study of a nasal specimen performed after the start of chemotherapy revealed the following findings: most tumor cells were highly positive for CD56, partially positive for desmin, positive for Periodic acid-Schiff (PAS) stain and negative for oxidase PAS (Fig. 6). The patient was ultimately diagnosed with rhabdomyosarcoma and bone marrow metastasis and clinically ranked as having Intergroup Rhabdomyosarcoma Study Group (IRSG) Stage IV disease (i.e., a high risk and poor prognosis) (12). A chromosome analysis demonstrated the presence of complex abnormalities (Table 1). Although the DIC was treated, and the patient was transfused with red blood cell concentrate (RCC), fresh frozen plasma (FFP) and platelet concentrate (PC), the DIC parameters peaked on day 11 after admission, with a fibrinogen level of $<30 \mathrm{mg} / \mathrm{dL}$ and an FDP level of $>800 \mu \mathrm{g} / \mathrm{mL}$. After three weeks of treatment, the bone marrow exhibited a complete response. The total dose of transfusion required during this period was 28 units of RCC, 540 units of PC and 120 units of FFP. After the first course of treatment, the patient's hematological toxicities included grade 4 neutropenia, grade 4 thrombocytopenia and grade 2 anemia, requiring no further transfusions. No signs of infection were documented, and the only non-hematological toxicity was 
Table 2. Laboratory Data

\begin{tabular}{lll}
\hline Bone marrow & aspiration & Cytogenetic analysis \\
$\mathrm{NCC}$ & $120,000 / \mu \mathrm{L}$ & $\mathrm{n}, \mathrm{XXX},-\mathrm{X},-1, \operatorname{add}(2)(\mathrm{q} 33) \times 2$, \\
$\mathrm{MgK}$ & $13 / \mu \mathrm{L}$ & $-3,-7, \operatorname{add}(9)(\mathrm{p} 11) \times 2,-11,-13,-13,-14,-15,+22,+\mathrm{mar}$ \\
$\mathrm{M} / \mathrm{E}$ & 16.0 & $(\mathrm{n}: 81=[1 / 20], 82=[1 / 20], 83=[1 / 20], 84=[4 / 20], 85=[10 / 20]$, \\
Blast-like & $94.8 \%$ & $86=[1 / 20], 87=[1 / 20])$ \\
Metamyelo & $0.2 \%$ & Specific staining \\
Stab & $0.2 \%$ & MPO $(-)$ \\
Seg & $2.8 \%$ & PAS $\quad(+)$ \\
Lympho & $1.4 \%$ & Immunostaining \\
M-Series & $3.2 \%$ & CD56 (+) \\
N-PolyErbl & $0.2 \%$ & CD45 (-) \\
Er-series & $0.2 \%$ & CD34 (-) \\
Macrophage & $0.2 \%$ &
\end{tabular}

grade 2 nausea.

A CT scan performed after nine weeks revealed that the primary lesion had completely disappeared. The patient thereafter completed all treatment and remained free of relapse for 15 months until developing brain metastasis. She continues to be alive with persistent disease, as of 26 months at the last follow-up.

\section{Discussion}

Although rhabdomyosarcoma is known to spread throughout the body, it primarily originates as a primary lesion in the head and neck region (29.4 to $40 \%)$, followed by the genitourinary track (20 to $25 \%$ ) and extremities (18 to $26.6 \%$ ) (13-15). Fewer than $25 \%$ of patients have distant metastasis at diagnosis, which mainly occurs in the lungs $(39 \%)$, bone marrow $(32 \%)$, lymph nodes $(30 \%)$, bones $(27 \%)$, omentum/ascites (16\%) and pleura (13\%) (16). As in the present case, bone marrow metastasis of rhabdomyosarcoma of head and neck origin is not thought to be rare. However, the prognosis of metastatic cases is poor (17-19), with a five-year event-free survival rate of $<30 \%$ (12), and outcomes are usually worse in adults than children $(20,21)$.

Bone marrow metastasis of rhabdomyosarcoma has been reported to be difficult to distinguish from acute leukemia, as both conditions exhibit diffuse involvement of blast-like cells $(6,8-10,22-34)$. In general, bone marrow metastasis of carcinoma can be distinguished from hematologic malignancies according to the presence of mass formation. However, rhabdomyosarcoma is difficult to distinguish from acute leukemia owing to the presentation of a bone marrow infiltration pattern with a loosely arranged distribution. We reviewed previously reported cases of rhabdomyosarcoma with bone marrow metastasis in the literature and found that it was difficult to distinguish this condition from leukemia at the primary examination in most cases (key words on PubMed: "rhabdomyosarcoma and leukemia," "rhabdomyosarcoma and bone marrow metastasis"). Table 3 presents rhabdomyosarcoma cases published since 1990 (6-10, 22-37). Most of these cases were initially considered to be leukemia due to the presence of cytopenia and blast-like cells in the peripheral blood, as well as a high percentage of atypical blast-like cells in bone marrow aspirates. Although Fitz- maurice reported a case in which a patient achieved a full remission with pulsed VAC (VCR, actinomycin D, CPA) and subsequently remained in good health until the end of chemotherapy (26), all other patients relapsed or died within two years (6-10, 22-37).

Some cases have been reported to have been treated based on an incorrect diagnosis. For instance, one patient was diagnosed with poorly differentiated malignoma of putative mesenchymal origin and treated with CPA+DXR+cisplatin (33). Another patient was diagnosed with very poorly differentiated leukemia and treated with methotrexate+prednisolone+VCR+L-asparaginase (8), while a third patient was diagnosed with acute myeloid leukemia, undifferentiated type, and treated with daunorubicin+cytarabine (10). In these cases, chemotherapy was initiated before obtaining a histological diagnosis due to the severity of the patients' conditions, and thus only findings for a morphological analysis and peroxidase staining of the bone marrow aspiration samples were available. Moreover, in some cases, no primary lesion was detected, which may have also led to an erroneous diagnosis.

In the present case, the patient's DIC status was not severe, and no bleeding was observed at the time of admission. Therefore, we were able to wait for the results of the flow cytometry analysis of the bone marrow cells, which revealed no lineage markers for myeloid, $\mathrm{T}$ or $\mathrm{B}$ cells. In addition, the presence of CD56-positive and CD45-negative cells in the present case suggests the possibility of neuroblastoma $(38,39)$, small cell carcinoma (40), rhabdomyosarcoma (38), Ewing's sarcoma (41) or a different type of neuroendocrine tumor (42). Furthermore, the tumor cells were positive for desmin on immunohistochemistry. Over 99\% of cases of rhabdomyosarcoma stain positive for polyclonal desmin; this is the essential finding for diagnosing rhabdomyosarcoma (43-46) (Fig. 6).

Many rhabdomyosarcoma cases involve the chromosomal translocation, $\mathrm{t}(2 ; 13)(\mathrm{q} 35 ; \mathrm{q} 14)$, in which the PAX3 gene is fused to the FKHR(FOXO1) gene $(47,48)$. This chromosomal translocation is found in $55 \%$ of cases of alveolar rhabdomyosarcoma, while the $\mathrm{t}(1 ; 13)(\mathrm{p} 36 ; \mathrm{q} 14)$ translocation, in which the PAX7 gene is fused to FOXO1, is detected in $22 \%$ of patients (49). These chromosomal translocations often serve as key findings for diagnosis. In the present 


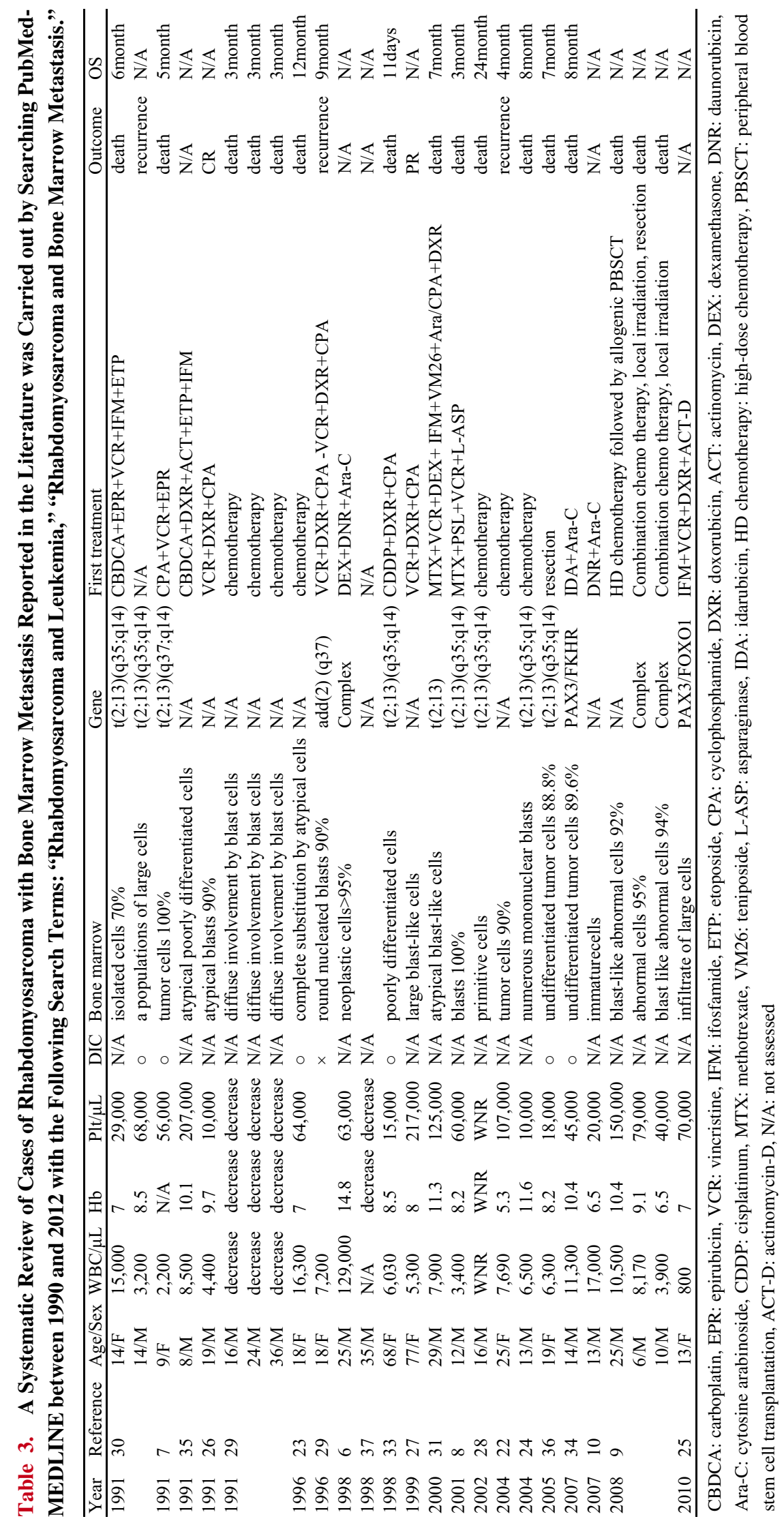


case, however, these translocations were not detected on a $\mathrm{G}$-Band test, and we were unable to further examine the gene fusions.

Rhabdomyosarcoma has a poor prognosis, except in individuals with the following characteristics: an age of 1 to 10 years, an embryonal histology, the absence of bone or bone marrow involvement and two or fewer sites of metastases. In most cases, the patient relapses or dies despite being correctly diagnosed and treated. Indeed, only a few reported adult patients have been reported to maintain complete remission for more than one year (26). According to the IRSG, the VAC regimen is recommended for high-risk rhabdomyosarcoma patients (50). However, we did not have access to actinomycin-D at our hospital at the time of diagnosis in this case, and it would have taken several days to obtain the drug, whereas our patient required urgent chemotherapy. Moreover, there is no definitive or established standard therapy for treating high-risk rhabdomyosarcoma patients, and the VAC regimen appears to be unsatisfactory for those with an estimated overall survival of less than $30 \%$. Arndt et al. reported the use of multi-agent therapy as an alternative to $\mathrm{VDC} / \mathrm{EI}$, followed by the administration of radiation therapy for the primary lesion, in intermediate-risk rhabdomyosarcoma patients with a five-year relapse-free survival rate of $82 \%$. In that study, the therapy proved promising, given that the relative risk of failure for the VDC/EI study compared to the Fourth Intergroup RMS Study (IRS-IV) is 0.5 (51). Moreover, the Soft Tissue Sarcoma Committee of the Children's Oncology Group (COG) is currently exploring the efficacy of VDC/EI therapy in addition to the application of interval compression of chemotherapy cycles and the administration of irinotecan in newly diagnosed patients with high-risk rhabdomyosarcoma. Accordingly, we chose multi-agent therapy for our patient.

In one report of a high-risk case, a long-term disease-free survival was achieved with allogeneic hematopoietic stem cell transplantation in order to induce a graft-versus-tumor effect (52). In our high-risk patient, the use of modified alternative VDC and EI therapy followed by radiation for the primary lesion successfully induced and maintained complete remission for 15 months.

In conclusion, the current patient exhibited bone marrow metastasis of rhabdomyosarcoma mimicking acute leukemia in morphology and presented with progressive deterioration following a nasal cavity tumor biopsy. However, a flow cytometry analysis of the bone marrow aspirate, as well as the morphology of the primary mass, as determined on staining with hematoxylin and eosin, aided the quick initiation of chemotherapy, resulting in complete remission. Therefore, physicians should consider rhabdomyosarcoma in the differential diagnosis of patients with DIC and blast-like cells in bone marrow aspirates showing negative staining for peroxidase. Moreover, if the patients is not in an urgent status (i.e., there are no signs of rapid progression of DIC or a severe bleeding tendency), clinicians should allow for a few days to perform a flow cytometry analysis of the bone mar- row aspirates.

The authors state that they have no Conflict of Interest (COI).

\section{References}

1. Parry TE. Proceedings: two cases of neuroblastoma with marrow findings mimicking acute leukaemia. Arch Dis Child 49: 497, 1974.

2. Lou Y, Meng H, Mao L, Jin J. Bone marrow relapse of medulloblastoma mimicking acute leukemia with translocation $(1 ; 18)$ (p33;q22). J Clin Oncol 29: e24-e26, 2011.

3. Anand M, Kumar R, Jain P, et al. Metastatic anaplastic oligodendroglioma simulating acute leukemia. A case report. Acta Cytol 47: 467-469, 2003.

4. Enzinger FM, Shiraki M. Alveolar rhabdomyosarcoma. An analysis of 110 cases. Cancer 24: 18-31, 1969.

5. McDowell HP. Update on childhood rhabdomyosarcoma. Arch Dis Child 88: 354-357, 2003.

6. Kahn DG. Rhabdomyosarcoma mimicking acute leukemia in an adult: report of a case with histologic, flow cytometric, cytogenetic, immunohistochemical, and ultrastructural studies. Arch Pathol Lab Med 122: 375-378, 1998.

7. Naito H, de Higa EH, Kobayashi R, Shikano T, Ishikawa Y, Nojima T. Alveolar rhabdomyosarcoma with massive bone marrow involvement and 2;13 chromosome translocation. Rinsho Ketsueki (The Japanese Journal of Clinical Hematology) 33: 238-243, 1992 (in Japanese, Abstract in English).

8. Sandberg AA, Stone JF, Czarnecki L, Cohen JD. Hematologic masquerade of rhabdomyosarcoma. Am J Hematol 68: 51-57, 2001.

9. Shinkoda Y, Nagatoshi Y, Fukano R, Nishiyama K, Okamura J. Rhabdomyosarcoma masquerading as acute leukemia. Pediatr Blood Cancer 52: 286-287, 2009.

10. Srinivas U, Pillai L, Kar R, Mahapatra M, Gujra S, Pati HP. A case of rhabdomyosarcoma masquerading as acute leukemia at presentation: a case report. Indian J Pathol Microbiol 50: 917-919, 2007.

11. Arndt CA, Nascimento AG, Schroeder G, et al. Treatment of intermediate risk rhabdomyosarcoma and undifferentiated sarcoma with alternating cycles of vincristine/doxorubicin/cyclophosphamide and etoposide/ifosfamide. Eur J Cancer 34: 1224-1229, 1998.

12. Raney RB, Anderson JR, Barr FG, et al. Rhabdomyosarcoma and undifferentiated sarcoma in the first two decades of life: a selective review of intergroup rhabdomyosarcoma study group experience and rationale for Intergroup Rhabdomyosarcoma Study V. J Pediatr Hematol Oncol 23: 215-220, 2001.

13. Wang C. Childhood rhabdomyosarcoma: recent advances and prospective views. J Dent Res 91: 341-350, 2012.

14. Dagher R, Helman L. Rhabdomyosarcoma: an overview. Oncologist 4: 34-44, 1999.

15. Ferrari A, Dileo $P$, Casanova $M$, et al. Rhabdomyosarcoma in adults. A retrospective analysis of 171 patients treated at a single institution. Cancer 98: 571-580, 2003.

16. Breneman JC, Lyden E, Pappo AS, et al. Prognostic factors and clinical outcomes in children and adolescents with metastatic rhabdomyosarcoma: a report from the Intergroup Rhabdomyosarcoma Study IV. J Clin Oncol 21: 78-84, 2003.

17. Wagemans J, Beuselinck B, Nuyts S, et al. A case series of embryonal rhabdomyosarcoma of the head and neck in adults. Acta Clin Belg 65: 404-410, 2010.

18. Callender TA, Weber RS, Janjan N, et al. Rhabdomyosarcoma of the nose and paranasal sinuses in adults and children. Otolaryngol Head Neck Surg 112: 252-257, 1995.

19. Prestidge BR, Donaldson SS. Treatment results among adults with 
childhood tumors: a 20-year experience. Int J Radiat Oncol Biol Phys 17: 507-514, 1989.

20. Lloyd RV, Hajdu SI, Knapper WH. Embryonal rhabdomyosarcoma in adults. Cancer 51: 557-565, 1983.

21. Nayar RC, Prudhomme F, Parise O Jr, Gandia D, Luboinski B, Schwaab G. Rhabdomyosarcoma of the head and neck in adults: a study of 26 patients. Laryngoscope 103: 1362-1366, 1993.

22. Ali R, Ozkalemkas F, Ozan U, et al. Rhabdomyosarcoma of the perianal region presenting as acute leukemia. Ann Hematol 83: 729-730, 2004.

23. Ambrosiani L, Bellone S, Betto FS, et al. Rhabdomyosarcoma presenting as acute hematologic malignancy: case report and review of the literature. Tumori 82: 408-412, 1996.

24. Chen L, Shah HO, Lin JH. Alveolar rhabdomyosarcoma with concurrent metastases to bone marrow and lymph nodes simulating acute hematologic malignancy. J Pediatr Hematol Oncol 26: 696697, 2004.

25. Curry S, Bacon CL, Robinson I, Capra M, Smith OP. Leukaemic alveolar rhabdomyosarcoma. Br J Haematol 151: 208, 2010.

26. Fitzmaurice RJ, Johnson PR, Yin JA, Freemont AJ. Rhabdomyosarcoma presenting as 'acute leukaemia'. Histopathology 18: 173175, 1991.

27. Haisa T, Kondo T, Miwa A, Saitoh K. Cervical epidural rhabdomyosarcoma with a leukemia-like presentation in an aged patient: case report. Neurol Med Chir (Tokyo) 39: 234-237, 1999.

28. Maywald O, Metzgeroth G, Schoch C, et al. Alveolar rhabdomyosarcoma with bone marrow infiltration mimicking haematological neoplasia. Br J Haematol 119: 583, 2002.

29. Morandi S, Manna A, Sabattini E, Porcellini A. Rhabdomyosarcoma presenting as acute leukemia. J Pediatr Hematol Oncol 18: 305-307, 1996.

30. Putti MC, Montaldi A, D’Emilio A, et al. Unusual leukemic presentation of rhabdomyosarcoma: report of two cases with immunological, ultrastructural and cytogenetical studies. Haematologica 76: $368-374,1991$.

31. Reinecke P, Gerharz CD, Thiele KP, et al. Temporary remission of an alveolar rhabdomyosarcoma diagnosed and treated as acute leukemia. Leuk Lymphoma 36: 405-409, 2000.

32. Sabattini E, Falini B, Pileri S. Rhabdomyosarcoma presenting as 'acute leukaemia'. Histopathology 19: 575-576, 1991.

33. Stindl R, Fiegl M, Regele H, Gisslinger H, Breitenseher MJ, Fonatsch C. Alveolar rhabdomyosarcoma in a 68-year-old patient identified by cytogenetic analysis of bone marrow. Cancer Genet Cytogenet 107: 43-47, 1998.

34. Yamaguchi K, Koga Y, Suminoe A, et al. Alveolar rhabdomyosarcoma of unknown origin mimicking acute leukemia at the initial presentation. Rinsho Ketsueki (The Japanese Journal of Clinical Hematology) 48: 315-320, 2007 (in Japanese, Abstract in English).

35. Locatelli F, Tonani P, Porta F, et al. Rhabdomyosarcoma with primary osteolytic lesions simulating non-Hodgkin's lymphoma. Pediatr Hematol Oncol 8: 159-164, 1991.

36. Miyoshi I, Uemura Y, Muneishi H, Miyazaki J, Taguchi H. Bone marrow metastasis of alveolar rhabdomyosarcoma. Intern Med 44: 677-678, 2005.

37. Pérez del Río MJ, Fresno Forcelledo MF, Ramírez Páyer A, et al.
[Alveolar rhabdomyosarcoma with massive infiltration of the bone marrow as its initial manifestation]. Sangre (Barc) 43: 236-239, 1998 (in Spanish, Abstract in English).

38. Mechtersheimer G, Staudter M, Moller P. Expression of the natural killer cell-associated antigens CD56 and CD57 in human neural and striated muscle cells and in their tumors. Cancer Res 51: 1300-1307, 1991.

39. Knapp W. Leucocyte typing IV: White Cell Differentiation Antigens. Oxford University Press, Oxford, 1989.

40. Chang A, Benda PM, Wood BL, Kussick SJ. Lineage-specific identification of nonhematopoietic neoplasms by flow cytometry. Am J Clin Pathol 119: 643-655, 2003.

41. Gardner LJ, Polski JM, Fallon R, Dunphy CH. Identification of CD56 and CD57 by flow cytometry in Ewing's sarcoma or primitive neuroectodermal tumor. Virchows Arch 433: 35-40, 1998.

42. Bryson GJ, Lear D, Williamson R, Wong RC. Detection of the CD56+/CD45- immunophenotype by flow cytometry in neuroendocrine malignancies. J Clin Pathol 55: 535-537, 2002.

43. Stock N, Chibon F, Binh MB, et al. Adult-type rhabdomyosarcoma: analysis of 57 cases with clinicopathologic description, identification of 3 morphologic patterns and prognosis. Am J Surg Pathol 33: 1850-1859, 2009.

44. Parham DM, Webber B, Holt H, Williams WK, Maurer H. Immunohistochemical study of childhood rhabdomyosarcomas and related neoplasms. Results of an Intergroup Rhabdomyosarcoma study project. Cancer 67: 3072-3080, 1991.

45. Truong LD, Rangdaeng S, Cagle P, Ro JY, Hawkins H, Font RL. The diagnostic utility of desmin. A study of 584 cases and review of the literature. Am J Clin Pathol 93: 305-314, 1990.

46. Dodd S, Malone M, McCulloch W. Rhabdomyosarcoma in children: a histological and immunohistochemical study of 59 cases. J Pathol 158: 13-18, 1989.

47. Shapiro DN, Sublett JE, Li B, Downing JR, Naeve CW. Fusion of PAX3 to a member of the forkhead family of transcription factors in human alveolar rhabdomyosarcoma. Cancer Res 53: 5108-5112, 1993.

48. Galili N, Davis RJ, Fredericks WJ, et al. Fusion of a fork head domain gene to PAX3 in the solid tumour alveolar rhabdomyosarcoma. Nat Genet 5: 230-235, 1993.

49. Sorensen PH, Lynch JC, Qualman SJ, et al. PAX3-FKHR and PAX7-FKHR gene fusions are prognostic indicators in alveolar rhabdomyosarcoma: a report from the children's oncology group. J Clin Oncol 20: 2672-2679, 2002.

50. Raney RB, Maurer HM, Anderson JR, et al. The Intergroup Rhabdomyosarcoma Study Group (IRSG): Major Lessons From the IRS-I Through IRS-IV Studies as Background for the Current IRS-V Treatment Protocols. Sarcoma 5: 9-15, 2001.

51. Arndt CA, Hawkins DS, Meyer WH, Sencer SF, Neglia JP, Anderson JR. Comparison of results of a pilot study of alternating vincristine/doxorubicin/cyclophosphamide and etoposide/ifosfamide with IRS-IV in intermediate risk rhabdomyosarcoma: a report from the Children's Oncology Group. Pediatr Blood Cancer 50: 33-36, 2008.

52. Ohta H, Hashii $Y$, Yoshida $H$, et al. Allogeneic hematopoietic stem cell transplantation against recurrent rhabdomyosarcoma. J Pediatr Hematol Oncol 33: e35-e38, 2011.

(C) 2015 The Japanese Society of Internal Medicine

http://www.naika.or.jp/imonline/index.html 